\title{
The Effects of Wiki Activities on Undergraduates' EFL Grammar Achievement and Its Relationship to Time on Task
}

\author{
Cooper Singman (Corresponding author) \\ Department of Applied Foreign Languages, Tatung University \\ 40, Sec. 3, Zhongshan N. Rd., Taipei City 104, Taiwan \\ Tel: 886-2-2182-2928 \#6802 E-mail: cooper@ttu.edu.tw
}

Hsin-Lin Lu

Department of English Language and Literature, Fu Jen Catholic University

510 Zhungzheng Rd, Xinzhuang Dist., New Taipei City, 24205 Taiwan

Tel: 886-2-2905-2000Ｅ-mail: hsinlinlu@gmail.com

Received: August 22, 2014 Accepted: September 4, 2014 Published: September 4, 2014

doi:10.5296/ijele.v2i2.6267 URL: http://dx.doi.org/10.5296/ijele.v2i2.6267

\begin{abstract}
The purpose of this study was to compare the effects of wiki-based language learning activities with Face-to-face (FTF) language learning activities on the development of English grammatical competence at a Taiwanese university. A quasi-experimental pretest/posttest design was utilized. A convenience sample of 84 EFL undergraduates officially enrolled in the college voluntarily participated in the study. An ANCOVA was conducted to assess whether wiki activities can bring about significantly better outcomes regarding English grammar usage. Results indicated that the wiki group significantly outperformed the FTF group. The results also indicated that there was a significant difference in students' time devoted to English grammar activities between the treatment group and the control group in favor of the treatment group. Furthermore, there was a statistically significant relationship between the time spent on wiki sites and students' English grammar achievement gains. The time students in the treatment group spent on grammar activities increased when they used the wiki. Overall, treatment group students' devotion to the wiki activities brought about effective language learning.
\end{abstract}

Keywords: wiki; EFL; grammar; time on task 


\section{Introduction}

\subsection{Background}

Research concluded that time on task has the most important influence on academic achievement (Slavin, 2003). As many EFL teachers know, there is the challenge of providing the number of hours in the target language that is required of fluent speakers. The number of hours teachers have the students in class cannot be increased, but additional hours outside of the class, with online collaborative social media such as wikis, can be provided. Now, students have the opportunity to engage more time to communicate and interact in English with native speakers, teachers as well as other learners from home.

In second/foreign language learning and teaching, the communicative competence theory presented by Canale and Swain (1980) is the most popularly accepted and embraced. Communicative competence encapsulates four areas of competence, among which grammatical competence is the first and the most crucial factor. Celce-Murcia, Larsen-Freeman and Williams (1999) maintained that the ultimate goal of grammar instruction is to equip students with communicative competence. Spada and Lightbown (1999) argued that after learners have acquired basic structures and vocabulary and have developed a basic ability to communicate, they should be devoted to form only due to its emphasis on authentic communication. Rodríguez (2009) also observed that, even in instances where learners are not completely ready to learn a form, profound focus-on-form instruction can help them learn other structures that are relevant to the target grammatical form.

Form-focused instruction and communicative language teaching (CLT) can be integrated through the use of grammar activities in computer-mediated communication (CMC) interactions, which are designed to encourage communication about grammar (Ellis, 2001). These grammar activities have two main purposes, namely to develop explicit second language (L2) grammatical knowledge and to provide opportunities for interaction focused on information exchange. They can be achieved in teacher-directed lessons or they can be used in computer-mediated group work, such as wikis, in order to increase opportunities for pushed output (Skehan, 2003).

Ideally, the best way to enhance motivation and to make English come alive for EFL learners is through authentic interactive communication which provides the opportunities of intensive exposure to the target language. It is also the best way to improve attitudes towards EFL, and to enhance achievement (Salaberry, 1996). Research studies show that one of the most effective ways to foster L2 development is through verbal interaction (either face-to-face or computer-mediated) with the target language speakers or learners (Warschauer, 1997). However, face-to-face interaction is not always possible, especially for the EFL students who rely on their time in classrooms to learn English that is not the typical language of communication outside the classroom, and who do not have the opportunity to participate in exchange visits.

With the development of wiki software and its increasing prevalence within the educational system, the questions then became, "do wikis really aid in the language learning process by 
providing learners with increased time on task"? Is it possible to enhance students' (including the majority who have no out-of-classroom contact with English) recognition of correct English grammar usage??

\subsection{Wiki}

The development of wiki software has created new ways for teachers to communicate with students, and it has been an asset from which many have profited. Many language teachers have adopted the use of wiki sites into their traditional teaching mechanisms as part of a blended-learning approach (Evans, 2009). According to Britannica Online Encyclopedia (wiki, 2012), a wiki is a website that can be edited or contributed to by users. "Wikis can be dated to 1995, when American computer programmer Ward Cunningham created a new collaborative technology for organizing information on web sites" (para. 1).Wikis are used in a wide variety of circumstances to expedite interaction and cooperation in projects of different aspects. Owing to some negative media broadcasting, many people hesitate to learn about and use wikis. Teachers especially may be hesitant as they are responsible for students' safety and copyright infringements (Chapelle, 2003). This is unfortunate because there are many wiki sites that are not only suitable for academic use, but also have the potential really to enrich a curriculum. Safko (2010) stated that: "wikis are websites that allow people to collect and edit their intelligence in one place at anytime. These web sites truly represent the social media foundation of user generated content and the wisdom of the crowds." (p. 159). The study that follows sought to construct a framework for this author's on-going research into the effect of applying online computer-mediated communication (CMC) tools, particularly wikis, in EFL classrooms.

\section{Theoretical Framework}

The theoretical framework presents selected influential past and recent theories of second language acquisition and language learning, namely the Input-Interaction-Output (IIO) Model, Sociocultural and Activity Theory (SCT/AT), and Collaborative/cooperative learning (CL).

\subsection{The Input-Interaction-Output (IIO) Model}

Over the last 20 years, there have been many second language acquisition (SLA) theories constructed. Past researchers have emphasized various aspects of SLA in their studies. Starting with the monitor model and input hypothesis, SLA study has extended to the IIO model (Block, 2003) as elaborated by researchers such as Gass (1997), Gass and Selinker (2001), and Long (1996). The role of the three connected hypotheses, namely input, interaction, and output has been acknowledged as an interdisciplinary theory in L2 learning. The input and interaction hypothesis (Long, 1985) combines a perspective with regard to the essence of input comprehension to SLA (e.g., Krashen's input hypothesis: 1983a, 1983b, 1985) and a stance for the importance of modifications to discourse structure for learner comprehension (e.g., Long's interaction hypothesis, 1985).

Both Long (1985) and Krashen (1985) viewed comprehensible input as a derivation of acquisition, but there are other theorists who argued that comprehensible input is not sufficient to reinforce acquisition. Consequently, Swain (1985) advanced what is called 
"comprehensible output" and studied the effectiveness of pushing language learners to produce language.

In fact, many studies revealed that foreign/second language students must be exposed to two steps of interaction. The first is the presence of comprehensible input in learner interactions, and the second is the chance for learners to structure their output grammatically (Swain 1985). Specifically, in pursuance of motivating the learner's interlanguage system toward the target language, situations to focus on communication deficiencies must be provided (Nakatani, 2005). These types of situations have been furnished to learners through informal group and pair work that push them to discourse in the target language.

\subsection{Sociocultural Theory (SCT)}

Sociocultural theory (SCT), which developed from the work of Vygotsky (1978), aim to account for important characteristics of the learning milieu at diverse aspects, from the individual aspect to the broader sociocultural milieu of teaching and learning (Levy \& Stockwell, 2006). Various proposals with regard to SCT and AT have become challengers to the cognitive and information-processing approach to the study of language (Lantolf, 2000). A number of studies on web-based collaboration have discovered that social interaction and collaboration play a significant role in the learning processes. From a sociocultural standpoint, language learning is considered to be an active social and collaborative process. Through it, learners use a system of symbols (e.g., language) and tools (e.g. computers) to build a system of linguistic paradigm, in collaborative interaction with other learners, to accomplish a task, rather than simply constructing transmitted language information from the outside world (Lantolf, 2000; Lee, 2009). By means of collaborative interaction, learners expand their linguistic and cognitive abilities to involve themselves in decision-making and problem-solving (e.g., negotiation of meaning and form) (Lee, 2009).

\subsection{Collaborative/Cooperative Learning (CL)}

Collaborative/cooperative learning (CL) is one of the most popular topics in the education industry. It is a strategy that implies that students would perform better if they were grouped with students of varying levels of ability (Slavin, 1995). The key idea is that students in a cooperative learning group would help each other learn (Levy \& Stockwell, 2006). CL research shows that its use in the classroom has pedagogical benefits. Collaborative activities in foreign language classrooms are found to be beneficial, because they provide opportunities for interaction and negotiation of meaning between learners (Swain 1995). Furthermore, it has been shown that when a collaborative learning environment is supported by computer-mediated communication $(\mathrm{CMC})$, its potential success for foreign language learning is remarkably enhanced (Levy \& Stockwell, 2006). CMC tools such as wikis could really help manage cooperative learning activities in the classroom. Wikis allow users easily to create and edit pages collaboratively. This $\mathrm{CMC}$ tool, therefore, has the potential to complement and enhance online collaboration.

\subsection{Wikis in Second Language Learning}

The development of wiki software has created new ways for teachers to communicate with 
students, and it has been an asset from which many have profited. Many language teachers have adopted the use of wiki sites into their traditional teaching mechanisms as part of a blended-learning approach (Evans, 2009). The best-known use of wiki software is Wikipedia, an online encyclopedia. In addition to encyclopedias, wikis are used in a wide variety of circumstances to expedite interaction and cooperation in projects of different aspects. Owing to some negative media broadcasting, many people hesitate to learn about and use wikis. Teachers especially may be hesitant as they are responsible for students' safety and copyright infringements (Chapelle, 2003). This is unfortunate because there are many wiki sites that are not only suitable for academic use, but also have the potential really to enrich a curriculum. Safko (2010) stated that: "wikis are websites that allow people to collect and edit their intelligence in one place at anytime. These web sites truly represent the social media foundation of user generated content and the wisdom of the crowds." (p. 159). The study that follows sought to construct a framework for this author's on-going research into the effect of applying online computer-mediated communication (CMC) tools, particularly wikis, in EFL classrooms.

Several studies have depicted how wikis are being used inthe L2 classroom to develop language skills(e.g., Bradley, Lindstrom, \& Rystedt, 2008;Chen, 2008; Kessler, 2009; Lee, 2009; Mak \& Coniam, 2008; Woo, Chu, Ho, \& Li, 2011), strengthen collaborative learning and enhancedcreative writing(e.g., Bradley, Lindstrom, \& Rystedt, 2008; Castañeda \& Cho, 2012; Coyle, 2007; Kessler, 2009; Kessler \& Bikowski, 2010; Lee, 2009; Mak \& Coniam, 2008; Woo, Chu, Ho, \& Li, 2011), especially in terms of college students' L2 grammatical knowledge and language accuracy (Castañeda \& Cho, 2012; Kessler, 2009; Lee, 2009), and facilitate peer feedback(Lee, 2009;Mak \& Coniam, 2008). Additionally, studies have highlighted positive perceptions using wikis, and students self-reported that wikis are useful and helpful for language learning (Castañeda \& Cho, 2012; Kessler, 2009; Lee, 2009; Woo, Chu, Ho, \& Li, 2011).

Despite the fact that there is a considerable collection of literature that has discussed the creation and use of wikis in both formal and informal educational settings, scientific research literature regarding actual recognition of correct English grammar usage and its relation to the time on task, barely exists. This study aims to investigate the effect of wikis on students' EFL grammar achievement by comparing the use of wiki-based activities to traditional face-to-face (FTF) activities.

\subsection{Purpose of the Study}

This quantitative study used a quasi-experimental, nonequivalent control group design with pretest and posttest. The purpose of this study was to compare the effects of wiki-based collaborative activities to traditional activities on the recognition of correct English grammar usage. The study also examined the time devoted to grammar activities and its effect on students' recognition of correct English grammar usage. Given the above information, the research questions examined in this study were:

1. Is there a significant difference between the treatment (wiki) group and the control (non-wiki) group's English grammar achievement levels after controlling for 
pre-intervention achievement levels?

2. Is there a difference in students' time devoted to English grammar activities between the treatment (wiki) group and the control (non-wiki) group?

3. Is there a relationship between the time spent on the wiki sites and students' English grammar achievement levels?

\section{Method}

\subsection{Participants}

College students from a suburban area of Taipei participated as intact groups in this study. The participants who represent the population were young adult male and female college EFL students who have received at least seven years of English as a required course. When planning the experiment, a power analysis was performed to estimate a sample size that will achieve statistically meaningful results. Given a significance level of .05 , assuming a moderate effect size and a desired power of 0.80 , a minimum sample size of 77 was sufficient. Therefore, two existing classes, with 84 sophomores majoring in English, were recruited as subjects in the study. These two classes were selected to participate as the treatment and control groups, and were taught by the same instructor. To be more detailed, the treatment group, consisting of 44 students, was using the wikis for group activities, while the control group, with 40 students, was practicing with the traditional English grammar exercises. Table 1 presents the demographic information of total subjects.

Table 1. Demographic Information of Total Participants

\begin{tabular}{lll}
\hline Demographic Variables & Frequency $(\mathrm{n})$ & Percentage $(\%)$ \\
\hline Gender & 27 & 32.1 \\
Male & 57 & 67.9 \\
Female & & \\
Age & 1 & 1.2 \\
18 & 41 & 48.8 \\
19 & 35 & 41.7 \\
20 & 5 & 6.0 \\
21 & 1 & 1.2 \\
22 & 1 & 1.2 \\
23 and above & & \\
Year learned English & 22 & 26.2 \\
2-5 years & 37 & 44.0 \\
$6-10$ years & 22 & 26.2 \\
$11-15$ years & 3 & 3.6 \\
16 years and above & & \\
\hline
\end{tabular}




\subsection{Instruments}

Two different data collection instruments were used in this study: a pre-post English grammar test; and a student survey.

\subsubsection{English Grammar Test}

The pretest and posttest both used the TOEIC (Test of English for International Communication) practice tests adapted and modified from TOEIC Test grammar and vocabulary review (n.d.) produced by TOEIC faculty at the University of California to test students' grammar comprehension abilities. The test consisted of questions in a multiple-choice format. In this study, the grammar portion of the test review was chosen to measure students' grammar achievements. Cronbach's alpha $(\alpha)$ reliability was performed to test the internal consistency of the test. The Cronbach's $\alpha$ for the grammar test was 0.78 , which has reached an acceptable level of reliability.

\subsubsection{Survey}

At the end of the treatment period, the students in the both groups completed a survey that includes demographic questions, and retrospective questions about time spent on the activities. The survey in this study was integrated from previous studies (Chen, 2011; Liaw, 2007), and was re-created by the researcher. The survey was translated from English to Chinese and was given to all students who participated in this study. The researchers asked the students to record honestly how many hours they spent on the wiki sites and practicing English grammar exercises. Therefore, students in the wiki group recorded the hours they spent on wiki activities, read and commented or edited other students' online postings, and practiced grammar exercises on the wiki sites. The students in the control group recorded the hours they spent on traditional individual and group activities, as well as practicing grammar exercises.

\subsection{Procedures}

The study took place over a four-week period in one semester. In terms of course content, this time frame corresponded to the time period of Unit 5 Chapter 3 and Unit 7 Chapter 2 of the textbook Reading \& Vocabulary Development 3: Cause \& Effect, for which the target grammar structures were taught, as scheduled in the course syllabus.

The pre-intervention data collection took place before the beginning of Unit 5. The pretest was administered to both classes to evaluate the students' previous recognition of correct English grammar usage. This instrument was administered by the instructor.

During the intervention period, the instructor taught the targeted grammar points. These grammar points were presented in the traditional face-to-face setting. Before technology training took place, the instructor divided the treatment group into 11 small groups. Correspondingly, the instructor divided the control group into 10 groups. Each group had four participants. Each group had a leader, and he or she encouraged group members to post, edit, and comment on the wiki. The instructor oversaw the participants' work and gave comments throughout the intervention period. 
Students in the wiki group were trained on how to use the wiki. The instructor explained what the students will be creating on the wiki site. The instructor handed out written instructions for each participant. After all students have accessed to their wiki sites, the instructor provided directions for the activities. Students posted their assignments outside class time by using their own computers or the ones in the college libraries or computer labs. Meanwhile, students in the control group were assigned the same activities in the traditional way with the same requirements and due dates. Detailed descriptions of the grammar activities are shown in Table 1.

By the end of semester, the post-intervention data collection took place. The student survey and posttest were administered by the instructor.

Table 1. Detailed Descriptions of Grammar Activities

\begin{tabular}{|c|c|c|}
\hline Activities & Descriptions & Grammar categories \\
\hline Activity 1: Hotlist & $\begin{array}{l}\text { By conducting Internet searches, } \\
\text { students create a hotlist of ten } \\
\text { web-based resources on a given } \\
\text { course-related grammar categories. }\end{array}$ & $\begin{array}{ll}\text { - } & \text { word forms } \\
\text { - } & \text { prepositions } \\
\text { - } & \text { conjunctions } \\
\text { - } & \text { verb tenses }\end{array}$ \\
\hline $\begin{array}{l}\text { Activity 2: Create } \\
\text { sentences }\end{array}$ & $\begin{array}{l}\text { Students create their own sentences } \\
\text { follow the patterns of the sample } \\
\text { sentences adapted from the text book. }\end{array}$ & - relative pronoun \\
\hline $\begin{array}{l}\text { Activity } \\
\text { Sample dialog }\end{array}$ & $\begin{array}{l}\text { Students work as pairs, compose a } \\
\text { dialog by using the sentences their } \\
\text { partner created. }\end{array}$ & \\
\hline $\begin{array}{l}\text { Activity 4: Short } \\
\text { story }\end{array}$ & $\begin{array}{l}\text { Students work as groups, compose a } \\
\text { short story by using the given sentence } \\
\text { patterns. }\end{array}$ & \\
\hline
\end{tabular}

\subsection{Data Analysis}

This study used quantitative measures to gather data from Taiwanese EFL students in order to analyze the effects of wiki-based collaborative activities on their English grammar achievement. An ANCOVA was conducted to test the mean differences of grammar scores between the treatment group and the control group, with the assigned activities as the 
independent variable and the measured variable as the dependent variable, and, the learners' prior knowledge of the target grammar structures as the covariate. A t-test was used to test if students in the wiki group devoted significantly more time to the activities than those students in the non-wiki group. Bivariate correlation analysis was used to find out the possibility of any correlation between the time spent on wiki sites and students 'English grammar achievements. All analyses were conducted using a .05 level of significance.

\section{Results}

\subsection{Research Question 1}

Research Question 1 asked: "Is there a difference in students' English grammar achievement levels between the treatment (wiki) group and the control (non-wiki) group after controlling for pre-intervention achievement levels?"

First, the scores of the students' pretests and posttests were calculated for both groups (Table 2 ). The mean of the pretest wiki group was $43.55(s d=12.57)$, and the mean of the pretest non-wiki group was $40.20(s d=16.28)$. The mean of the posttest wiki group was 51.00 $(s d=14.69)$, and the mean of the posttest non-wiki group was $41.90(s d=14.26)$. When assessing the gain, scores overall increased in the grammar test, the treatment group having a gain score mean of 7.45, and the control group having a gain score mean of 1.7 .

Table 2. Participating Students' Grammar Scores by Group

\begin{tabular}{lccccc}
\hline Group & Pretest & \multicolumn{3}{c}{ Posttest } & Difference \\
& Mean & SD & Mean & SD & \\
Wiki & 43.55 & 12.57 & 51.00 & 14.69 & 7.45 \\
Non-wiki & 40.20 & 16.28 & 41.90 & 14.26 & 1.7 \\
\hline
\end{tabular}

To answer Research Question 1, an analysis of covariance (ANCOVA) was conducted to test for the group difference on the grammar posttest scores. The pretest scores were used as the covariate. Before an ANCOVA, the homogeneity-of-slope assumption (Table 3) was tested to find out if the interaction between the covariate and the factor in predicting the dependent variable is significant or not. The interaction source is labeled Groups*Pre. The interaction was not significant, $\mathrm{F}(1,80)=.28, \mathrm{p}=.60$. 
Table 3. Tests of Homogeneity of Slope

\begin{tabular}{lllllll}
\hline Source & \multicolumn{2}{l}{ Type III Sum of Df } & Mean Square F & Sig. & $\begin{array}{l}\text { Partial Eta } \\
\text { Squared }\end{array}$ \\
& Squares & & & & & \\
Corrected Model & 11515.72 & 3 & 3838.57 & 41.281 & .00 & .61 \\
Intercept & 1724.62 & 1 & 1724.62 & 18.547 & .00 & .19 \\
Groups & 21.30 & 1 & 21.301 & .229 & .63 & .003 \\
PreScores & 9542.20 & 1 & 9542.20 & 102.62 & .00 & .56 \\
Groups * PreScores & 192.22 & 1 & 26.06 & 0.28 & .60 & .003 \\
Error & 7438.95 & 80 & 92.987 & & & \\
Total & 201888.00 & 84 & & & & \\
Corrected Total & 18954.67 & 83 & & & & \\
\hline
\end{tabular}

Since the interaction was not significant, an ANCOVA was conducted. The results of the ANCOVA (Table 4) indicated that the difference on the grammar post-scores between the two groups was significant after controlling for the pretest performance, $F(1,81)=9.70, p=.003$ which was less than .01. The strength of the relationship between the intervention and dependent variable was moderately large, as assessed by partial Eta squared, with the intervention factor accounting for $10.7 \%$ of the variance of the dependent variable, holding constant the grades of pre-test (Partial $\eta 2=.107)$.

Table 4. Analysis of Co-variance (ANCOVA) for student levels

\begin{tabular}{lllllll}
\hline Source & SS & Df & Mean Square & F & Sig. & $\begin{array}{l}\text { Partial Eta } \\
\text { Squared }\end{array}$ \\
\hline Pre-test & 9754.60 & 1 & 9754.60 & 105.84 & .000 & .566 \\
Group & 893.58 & 1 & 893.58 & 9.70 & $.003^{*}$ & .107 \\
Error & 7465.01 & 81 & 92.16 & & & \\
Total & 201888.00 & 84 & & & & \\
\hline
\end{tabular}

* Significance level was set on $\mathrm{P}<0.01$.

The test also assessed the difference between the adjusted means for the two groups, which are reported in the output as the Estimated Marginal Means (49.80, 43.22). The difference 
between the adjusted means for the two groups was not the same as the difference between the means on the dependent measure $(51.00,41.90)$, in that the two groups had differing grades of pre-test (Table 5).

Table 5. Estimated Marginal Means

\begin{tabular}{lll} 
Group & M & SEM \\
\hline Wiki & 49.80 & 1.45 \\
Non-wiki & 43.22 & 1.52
\end{tabular}

\subsection{Research Question 2}

Research Question 2 asked: Is there a difference in students' time devoted to English grammar activities between the treatment (wiki) group and the control (non-wiki) group?

To answer Research Question 2, first, the mean of the participating students' self-reported time devoted to English grammar activities between the treatment (wiki) group and the control (non-wiki) group were calculated (Table 6).

Table 6. Participating Students' Self-reported Time by Group Time=Hour(s) per week

\begin{tabular}{lllll} 
Group & Wiki & \multicolumn{3}{c}{ Non-wiki } \\
& Mean & SD & Mean & SD \\
\hline Time & 2.27 & 1.04 & 1.78 & 1.14
\end{tabular}

The mean time for the non-wiki group was 1.78 with a standard deviation of 1.14; the mean time for the wiki group was 2.27 with a standard deviation of 1.04 . This demonstrates that students in the treatment group, on average, spent more time on English grammar activities than did the control group.

In addition to the descriptive statistics, independent samples $t$ - tests, illustrated in Table 7, were conducted on the time spent for both groups. The test was significant, $t(82)=2.087$, $p=.04$. The $95 \%$ confidence interval for the difference in means was from .023 to 0.97. 
Table 7. Independent Samples t Test: Time Spent on English Grammar Activities

$\begin{array}{cccc}\text { Group } & \text { Source } \quad D f \quad t \quad & & 95 \% \text { Confidence Interval } \\ & \text { of the Difference }\end{array}$

\begin{tabular}{ll}
\hline Lower Upper \\
\end{tabular}

Wikivs.

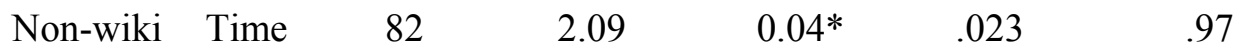

* Significance level was set on $\mathrm{P}<0.01$.

\subsection{Research Question 3}

Research Question 3 asked: "Is there a relationship between the time spent on the wiki sites and students' English grammar achievement levels?" To answer Research Question 3, first, the scores of the students' pretests to posttests gains were calculated for the wiki group (Table $8)$. The mean gain was $7.45(s d=10.97)$. Correlations were examined between the time spent on wiki sites and students' English grammar achievement gains. The results of the correlational analyses indicated that there was a large, statistically significant relation between the time spent on wiki sites and students' English grammar achievement gains ( $\mathrm{r}$ $=.412, \mathrm{p}<.01)$. According to Cohen $(1988)$, a correlation of 0.5 is large, 0.3 is moderate, and 0.1 is small. The result shows that if students spend more time on wiki sites, they gain higher scores on English grammar as well.

Table 8. Descriptive Statistics

\begin{tabular}{llllll}
\hline Test Score Gains & N & Min & Max & Mean & SD \\
\hline Wiki group & 44 & -20.00 & 28.00 & 7.45 & 10.97 \\
\hline
\end{tabular}

In sum, the results supported the first hypothesis that there is a difference in the means of the achievement posttest scores on the recognition of correct English grammar usage between the treatment (wiki) group and the control (non-wiki) group, in favor of the treatment group, when controlling for pre-existing knowledge. The results of the second research question indicated that there is a statistically significant difference in students' time devoted to English grammar activities between the treatment group and the control group in favor of the treatment group. The results also supported the third hypothesis that there is a statistically significant relationship between the time spent on wiki sites and students' pretest to posttest 
gains on English grammar achievement levels.

\section{Discussion and Conclusion}

\subsection{Discussion}

The first research question asked what effects wiki activities had on students, when compared to traditional activities, regarding the recognition of correct English grammar usage. The results of the data analysis showed that there is a statistically significant difference in the means of the achievement posttest scores on the recognition of correct English grammar usage $(F(1,81)=9.70, p=.003)$ between the treatment (wiki)group and the control (non-wiki) group in favor of the treatment group.

The second research question looked at whether or not there is a difference in students' time devoted to English grammar activities between the treatment (wiki)group and the control (non-wiki) group. The result of the t-test was statistically significant. There is a statistically significant difference in students' time devoted to English grammar activities $(t(82)=2.087$, $p=.04$ ) between the treatment group and the control group in favor of the treatment group.

The third research question examined the correlation between the time spent on wiki sites and students' English grammar achievement levels. Results of Bivariate correlation analysis indicated there is a statistically significant relationship between the time spent on wiki sites and students' English grammar achievement levels $(\mathrm{r}=.412, \mathrm{p}<.01)$.

These statistical findings were supported by other researchers such as Castañeda and Cho (2012), Chen (2008), Kessler (2011), Kessler and Bikowski (2010),Lee (2009), and Woo, Chu, Ho, and Li (2011) who conducted similar studies involving wikis and FL/EFL learning. These researchers agreed that wiki activities enhance students' abilities to increase their learning and performance of the correct English usage. Students not only helped each other organize the content but also made error corrections for language accuracy and, as a result, they concluded that a collaborative wiki task is a rewarding experience for language learners.

It was stated in the theoretical framework that the foundation of this study was based on second language acquisition and language learning, namely the Input-Interaction-Output (IIO) Model, computer assisted language learning (CALL) and Collaborative/cooperative learning (CL) theories. The results of the present study seem to agree with researchers, such as Swain (2000, 2001) and Takashima and Ellis (1999), who attempted to connect learners' opportunities for output more directly to second language acquisition, particularly in the area of grammatical structure. In their experiments, as learners endeavored to produce the target language, they realized that they were not able fully to express themselves, and this "pushes" them to reach better accuracy. Meanwhile, Swain (2000) concluded that, as learners engaged in output during collaborative interaction, they were able to help each other deliberate on the language usage, conjecture about language structure, and, acquire the target language in the process.

This study provides a valuable starting point for wiki-based collaborative language-learning research. It implies that the recommendations in the IIO model (Block, 2003) can be met by 
implementing collaborative activities that use wikis for the EFL classroom in a Taiwanese university setting. This gives teachers a tool for changing the classroom from transferring information through lecture to a classroom of interactive communication between students and teachers. It has been shown that, when a collaborative learning environment is supported by computer-mediated communication $(\mathrm{CMC})$, its potential success for foreign language learning is remarkably enhanced (Levy \& Stockwell, 2006). Furthermore, when the students engaged in collaborative patterns of interaction, they were more likely to perform better in the posttest. Today's Taiwanese college students are very comfortable using social media. It is important that foreign language teachers become more comfortable with social media to acknowledge the value of integrating it into their instruction.

Wiki-based social media has opened a new horizon for foreign language learning and teaching involving correct grammar usage. The present study showed that the ways the students used the wikis for collaborative and interactive grammar learning was pedagogically effective. With more time devoted to collaborative wiki assignments, students developed a powerful effect on EFL grammar learning. Moreover, grammar learning accompanied by interactive wiki activities can improve time on task. Teachers should increase out-of-class opportunities to help students by bring about discussions that are related to correct grammar usage. They should preview the grammar points in a reading passage, teach high-frequency grammar points, and help students create sentences or write up dialogues by using those grammar points.

\subsection{Limitations}

A number of limitations must be recognized in an interpretation of the results of this study. One of these limitations is the non-random selection procedure. This study contained only 84 students from two existing classes in one Taiwanese university. The research results might be different if the study was conducted in different settings. This was only one study at one university; therefore, the researchers urge future research on this topic. Besides, due to the retrospective survey employed in the present research and the lack of qualitative data, it is unknown to what extent the time on task improved positively on students' achievement and how students participated in the group interaction. Finally, the wiki sites themselves pose their own limitations. Although the students were given enough chances to interact and communicate on the wikis, they did not practice speaking the target grammar usage during the activities. For this reason, the use of wiki activities cannot replace actual oral practice in the target language.

\subsection{Recommendations for Further Research}

This study focused on English grammar achievement and the amount of time spent on grammar activities using wiki-based collaborative social media. Subjects in the treatment and control groups were tested and surveyed. The effects of wiki activities and traditional activities on the acquisition of targeted English grammar usage were compared. When analyzing this study, areas were found that could be further researched in the future. First, the present study took place over a total period of 4 weeks and used 84participants in two existing classes from one university in Taiwan. Further research could be conducted with 
larger samples and over a longer period of time to determine if findings can be generalized. It is also recommended that future studies include different types of social media, such as podcasting or videoconferencing, so students get chances to practice listening and speaking the target grammar usage during the activities. Finally, it is believed that the addition of qualitative data could have enriched the present research study, for it would have allowed further insights into the students' achievement and satisfaction levels. Future research should be conducted to study the quality as well as quantity of the interaction between learners. A mixed-methods study would be ideal for future research. Lastly, future studies should follow up on issues raised by Coyle (2007), who reported that there was no significant difference in students' achievement and perceptions between a wiki group and a traditional face-to-face group. Further research is needed to see how these results might have occurred and whether they hold true in subsequent research.

\subsection{Conclusion}

Based on a review of the literature, this study was the first quasi-experimental research in second language acquisition to explore the effects of wiki activities on EFL grammar. Previous studies have explored the effects of wiki-based social media language learning activities on multiple variables. This topic was explored by focusing on EFL grammar achievement and time-on-task.

The findings showed that the wiki group's test scores increased significantly from pretest to posttest than non-wiki (control) group. Also, there was a statistically significant difference in students' time devoted to English grammar activities between the treatment and control groups in favor of the treatment group. In addition, the results of the bivariate correlation analysis indicated there is a statistically significant relationship between the time spent on wiki sites and students' English grammar achievement levels. In sum, the study revealed that the use of collaborative wiki activities is positively correlated with the EFL student grammar achievement. Although both treatment and control groups showed achievement gains from pretest to posttest, the wiki group showed greater overall gains than the non-wiki group. The time students in the treatment group spent on grammar activities increased when they used the wikis, and they self-reported spending more time on task during free time. Students' devotion to the wiki activities brought about effective peer support and collaborative learning.

The overall conclusion from this study is that collaborative wiki activities can help students in their progress toward learning a foreign language. More research is needed to see if these findings can be replicated in other settings with different populations.

\section{References}

Block, D. (2003). The social turn in second language acquisition: Washington, DC: Georgetown University Press.

Bradley, L., Lindstrom, B., \& Rystedt, H. (2010).Rationalities of collaboration for language 
learning in a wiki.ReCall. 22(2), 247-265

Canale, M., \& Swain, M. (1980). Theoretical bases of communicative approaches to second language teaching and testing. Applied linguistics, 1(1), 1-47

Castañeda, D., \& Cho, M. (2012). The role of wiki writing in learning Spanish grammar.Computer Assisted Language Learning.

Celce-Murcia, M., Larsen-Freeman, D., \& Williams, H. A. (1999). The grammar book: an ESL/EFL teacher's course. Boston: Heinle \& Heinle.

Chapelle, C. A. (2003). English language learning and technology: Lectures on applied linguistics in the age of information and communication technology. Amsterdam: John Benjamins Publishing.

Chen, Y. (2008). The effect of applying wikis in an English as a foreign language (EFL) class in Taiwan. (Doctoral dissertation, University of Central Florida, 2008).

Chen, Y. (2011). The influence of integrating technology in language learning courses (Doctoral dissertation, University of Kansas, 2011).

Cohen, J. (1988). Statistical power analysis for the behavioral sciences (2nd ed.). Hillsdale, N.J.: L. Erlbaum Associates.

Coyle Jr, J. E. (2007). Wikis in the College Classroon: A Comparative Study of Online and Face-to-Face Group Collaboration at a Private Liberal Arts University (Doctoral dissertation, Kent State University).

Ellis, R. (2001). Form-focused instruction and second language learning. Malden, MA: Blackwell.

Evans, M. (2009).Foreign-language learning with digital technology. New York: Continuum.

Gass, S. M. (1997). Input, interaction, and the second language learner.Mahwah, NJ: Lawrence Erlbaum.

Gass, S., \& Selinker, L. (2001). Second language acquisition: An introductory course (2nd ed.).Mahwah, NJ: Lawrence Erlbaum.

Kessler, G. (2009). Student-initiated attention to form in wiki-based collaborative writing. Language Learning \& Technology, 13(1), 79-95.

Kessler, G. \& Bikowski, D. (2010). Developing collaborative autonomous learning abilities in computer mediated language learning: Attention to meaning among students in wiki space. Computer Assisted Language Learning, 23(1), 41-58.

Krashen, S. (1983a). Practical applications of research. Psycholinguistic Research ACTFL Yearbook, 54-65.

Krashen, S. D. (1983b). The din in the head, input, and the language acquisition device. Foreign Language Annals, 16(1), 41-44. 
Krashen, S. D. (1985). The input hypothesis. London: Longman.

Krashen, S. (1994).The input hypothesis and its rivals. In N. Ellis (Ed.)Implicit and explicit learning of languages, (pp. 45-77).London: Academic Press.

Lantolf, J. (2000). Second language learning as mediated process. Language Teaching, 33(2), 79-96.

Lee, L. (2009). Promoting intercultural exchanges with blogs and podcasting: A study of Spanish-American telecollaboration. Computer Assisted Language Learning, 22(5), 425-443.

Levy, M., \& Stockwell, G. (2006). CALL dimensions: Options and issues in computer-assisted language learning. Mahwah, NJ: Lawrence Erlbaum.

Liaw, M. (2007). Content-based reading and writing for critical thinking skills in an EFL context. English Teaching and Learning, 31(2), 45-87.

Long, M.H. (1985). Input and second language acquisition theory. In S. Gass \&C. Madden (Eds.), Input in second language acquisition (pp. 377-393).Rowley, MA: Newbury House.

Long, M. H. (1996). The role of the linguistic environment in second language acquisition. Handbook of Second Language Acquisition, 2, 413-468.

Mak, B., \& Coniam, D. (2008). Using wikis to enhance and develop writing skills among secondary school students in Hong Kong. System, 36(3), 437-455.

Nakatani, Y. (2005). The Effects of Awareness Raising Training on Oral Communication Strategy Use. The Modern Language Journal, 89(1), 76-91.

Rodríguez, A. G. (2009). Teaching grammar to adult English language learners: Focus on form. Washington, DC: Center for Applied Linguistics.

Safko, L. (2010). The Social Media Bible: Tactics, Tools, and Strategies for Business Success: John Wiley \& Sons.

Salaberry, M. R. (1996). A theoretical foundation for the development of pedagogical tasks in computer mediated communication. Calico Journal, 14(1), 5-34.

Skehan, P. (2003). Focus on form, tasks, and technology. Computer Assisted Language Learning, 16(5), 391-411.

Slavin, R. E. (1995).Cooperative learning: theory, research, and practice. Boston: Allyn and Bacon.

Slavin, R. E. (2003). Educational psychology: Theory and practice. Boston: Pearson Education.

Spada, N., \& Lightbown, P. M. (1999). Instruction, First Language Influence, and Developmental Readiness in Second Language Acquisition. The Modern Language Journal, 83(1), 1-22.

Swain, M. (1985). Communicative competence: Some roles of comprehensible input and 
comprehensible output in its development. In S. M. Gass, \& C. G. Madden (Eds.). Input in second language acquisition (pp. 235-253). Rowley, MA: Newbury House Publishers.

Swain, M. (1995). Three functions of output in second language learning. In H. G. Widdowson, G. Cook, \& B. Seidlhofer (Eds.).Principle \& practice in applied linguistics: studies in honour of H.G. Widdowson (pp. 125-144). Oxford: Oxford University Press.

Swain, M. (2000). The output hypothesis and beyond: Mediating acquisition through collaborative dialogue. In J. P. Lantolf (Ed.). Sociocultural theory and second language learning(pp. 97-114).Oxford: OxfordUniversity Press.

Swain, M. (2001). Integrating language and content teaching through collaborativetasks. Canadian Modern Language Review, 58, 44-63.

Takashima, H., \& Ellis, R. (1999).Output enhancement and the acquisition of the past tense. In R. Ellis (Ed.), Learning a second language through interaction (pp. 173-188): Philadelphia, PA: Benjamins.

TOEIC Test grammar and vocabulary review (n.d.) Retrieved from http://www.testwise.com/page/page/2752573.htm

Vygotsky, L. S. (1978). Mind and society: The development of higher mental processes. Cambridge, MA: Harvard University Press.

Warschauer, M. (1996). Comparing face to face and electronic discussion in the second language classroom. Calico Journal, 13, 7-26.

wiki. (2012). In Encyclopcedia Britannica. Retrieved from http://www.britannica.com/EBchecked/topic/1192819/wiki

Woo, M., Chu, S., Ho, A., \& Li, X. (2011). Using a wiki to scaffold primary-school students' collaborative writing. Subscription Prices and Ordering Information, 14(1), 43-54.

\section{Copyright Disclaimer}

Copyright for this article is retained by the author(s), with first publication rights granted to the journal.

This is an open-access article distributed under the terms and conditions of the Creative Commons Attribution license (http://creativecommons.org/licenses/by/3.0/). 